\title{
ldentificação dos procedimentos de fronteira críticos na importação de cargas conteinerizadas: estudo do Porto de Santos
}

\author{
Patricia Kuzmenko Furlan ${ }^{a *}$, Marcos Mendes de Oliveira Pinto ${ }^{\mathrm{b}}$ \\ a*patricia@kuzmenko.com.br, USP, Brasil \\ bmorpinto@usp.br, USP, Brasil
}

\begin{abstract}
Resumo
Este artigo identificou as principais práticas ou procedimentos desempenhados pelos órgãos governamentais brasileiros que culminam com lentidão e atrasos na importação de cargas conteinerizadas pelo Porto de Santos. A pesquisa foi conduzida em duas etapas: (1) levantamento das principais rotas logísticas e dos procedimentos de fronteira; (2) identificação da inter-relação dos fluxos físico e burocrático. As análises centraram-se nos procedimentos aduaneiros, que incluem a nacionalização e os procedimentos preliminares ou complementares. Foi notado que diferentes procedimentos e práticas contribuem para atrasos e retenção das cargas conteinerizadas, sendo eles conteúdos da nacionalização ou não.
\end{abstract}

Palavras-chave

Procedimentos aduaneiros. Carga conteinerizada. Tempo.

\section{Introdução}

A globalização tem estimulado o aumento das trocas internacionais de bens, estabelecendo cadeias de suprimentos globalmente integradas. Embora exista a tendência de unificação dos mercados globais, como defendido por Fleury \& Fleury (2011), uma série de especificidades são recorrentes nos países, inclusive os procedimentos de fronteira aplicados localmente pelos países. Quando ineficientes e excessivamente burocráticos, prejudicam a velocidade do trânsito internacional.

Os procedimentos de fronteira são aplicados por órgãos governamentais com o intuito de proteger o país contra a entrada ou a saída de bens irregulares; ou que ameacem a economia ou que degradem a biodiversidade local. A eles se aplica o controle aduaneiro desempenhado pela Receita Federal do Brasil (autoridade aduaneira), que assegura a regularidade tributária e as exigências de fronteira nas operações de importação e exportação; o controle sanitário das cargas e das embarcações pela ANVISA; a fiscalização fitozoossanitária do MAPA, dentre outros.
O Banco Mundial publicou dois estudos Doing Business (World Bank \& International Finance Corporation, 2013) e Connecting to Compete (Arvis et al., 2012) que contemplam estimativas do tempo despendido para a importação e exportação por diversos países, incluindo-se o Brasil. Por meio da Tabela 1 pode-se visualizar o tempo (em dias) para a importação brasileira e para os países com melhor desempenho logístico que, no caso, são Alemanha, Cingapura, Holanda, Hong Kong e Estados Unidos. No caso brasileiro, o tempo mostrou-se superior em todos os quesitos.

A retenção prolongada das cargas nas fronteiras implica em maiores custos aos importadores e exportadores que, como colocam Arvis et al. (2012), possuem componentes de custos diretos e indiretos, que prejudicam a competitividade das operações. Segundo lwanow \& Kirkpatrick (2009, p.1040),

[...] a habilidade dos países em desenvolvimento de se conectarem com mercados globais está sendo 
Tabela 1. Tempo para nacionalização (em dias), segundo o Banco Mundial.

\begin{tabular}{lccc}
\hline & $\begin{array}{c}\text { Nacionalização e controle técnico } \\
\text { (Doing Business, 2013) }\end{array}$ & $\begin{array}{c}\text { Nacionalização sem inspeção física } \\
\text { (Connecting to Compete, 2012) }\end{array}$ & $\begin{array}{c}\text { Nacionalização com inspeção física } \\
\text { (Connecting to Compete, 2012) }\end{array}$ \\
\hline Alemanha & 1 & 0 & 1 \\
Cingapura & 1 & 0 & 1 \\
Holanda & 1 & 0 & 1 \\
Hong Kong & 1 & 0 & 0 \\
Estados Unidos & 1 & 1 & 3 \\
Brasil & 4 & 2 & 5 \\
\hline
\end{tabular}

Fonte: World Bank \& International Finance Corporation (2013); Arvis et al. (2012).

cada vez mais afetada pelos custos que as empresas privadas possuem para o comércio internacional.

0 encarecimento das operações acaba repercutindo, então, na competitividade do comércio exterior, “[...] cujo ônus reflete-se em diversos setores da economia do país" (Furlan, 2013, p.21). Como concluído por Djankov, Freund e Pham (2006), cada dia de atraso para embarque dos contêineres (no caso da exportação) reduz o comércio desse país em pelo menos 1\%. Assim, considerando-se 33\% a parcela do PIB brasileiro referente ao comércio exterior (em 2012 o PIB brasileiro foi avaliado em US\$ 2,223 trilhões), tem-se que um dia de atraso na liberação das mercadorias acarreta numa perda de US\$ 7,33 bilhões ao país.

Devido à relevância do tempo e dos custos nas operações do comércio exterior, objetivou-se, neste artigo, identificar os principais procedimentos de fronteira ou de práticas que culminam com lentidão e atrasos na importação brasileira. Para tanto, o estudo foi conduzido como estudo de caso do Porto de Santos, o maior porto marítimo da América Latina que, segundo Antaq (Agência Nacional de Transportes Aquaviários, 2010), foi responsável por cerca de 40\% das movimentações no país.

\section{Método de pesquisa}

A metodologia utilizada neste artigo contemplou as pesquisas bibliográfica e em campo para o levantamento dos principais procedimentos de fronteira que culminam com atrasos e lentidão para a liberação das cargas conteinerizadas importadas por Santos. Isto ocorreu devido à escassez de publicações sobre o tema e pela necessidade de se ir a campo para a constatação da gestão operacional das cargas importadas pela via marítima.

Por meio de contato pessoal em forma de entrevistas foram consultados cerca de dez profissionais, dentre eles despachantes aduaneiros, fiscais federais, pesquisadores e executivos de associações ligadas ao setor portuário. As principais instituições consultadas na pesquisa em campo foram:
- ABEPRA (Associação Brasileira dos Portos Secos);

- ABTP (Associação Brasileira dos Terminais Portuários);

- ABTRA (Associação Brasileira de Terminais e Recintos Alfandegados);

- ANVISA (Agência Nacional de Vigilância Sanitária);

- CEGN (Centro de Estudos em Gestão Naval);

- CODESP (Companhia Docas de São Paulo);

- ICEX (Instituto de Estudos das Operações de Comércio Exterior);

- PROCOMEX (Instituto Aliança Pró Modernização Logística do Comércio Exterior);

- VIGIAGRO (Sistema de Vigilância Agropecuário Internacional).

A pesquisa foi realizada sob a forma de estudo de caso do Porto de Santos devido às especificidades operacionais que os portos marítimos brasileiros possuem e pela representatividade que esse porto tem no comércio exterior do país. As diferenças da gestão operacional entre portos abrangem sistemas de informação, disponibilidade de fiscais federais, existência de documentos locais, dentre outras questões. Desse modo foram abordados procedimentos nacionais para importação de cargas conteinerizadas em conjunto com as especificidades de Santos.

A pesquisa foi realizada em duas etapas: (1) Levantamento dos principais procedimentos de fronteira e das rotas logísticas e (2) 1dentificação da inter-relação entre os fluxos físico e burocrático. Ambas as etapas contemplaram as pesquisas bibliográfica e em campo para o levantamento de informações.

\subsection{Levantamento dos principais procedimentos de fronteira e das rotas logísticas}

A primeira etapa objetivou a identificação dos principais procedimentos que incidem nas importações brasileiras, onde foram, também, estudadas as opções logísticas que as cargas conteinerizadas assumem a partir de Santos. 
Foram utilizados diferentes canais de informação para o levantamento de informações, incluindo-se pesquisas acadêmicas, publicações governamentais e consulta às instituições listadas anteriormente. $\mathrm{Na}$ pesquisa bibliográfica, os principais autores identificados foram Vianna Junior (2009), Penha (2010) e Furlan (2013). O primeiro mapeou os procedimentos portuários do Porto de Santos segundo o SISPORTOS (um estudo realizado pelo governo federal para aperfeiçoamento dos sistemas de informação dos portos marítimos); o segundo explorou os recintos alfandegados externos ao Porto de Santos - os CLIAs (Centros Logísticos Industriais Aduaneiros) e as EADls (Estações Aduaneiras do Interior) - classificando-os como "poros territoriais", pois permitem a nacionalização dos importados em locais interioranos no território nacional (fora da área dos portos organizados marítimos). Furlan (2013) elaborou uma análise crítica dos procedimentos de Santos.

\subsection{Identificação da inter-relação entre os fluxos físico e burocrático}

Feito o levantamento inicial descrito no item 2.1, este segundo momento contemplou o estudo da inter-relação entre os fluxos físico e burocrático, o qual permitiu a identificação de pontos críticos nos processos. Para a avaliação, procedeu-se à identificação da frequência de ocorrência de cada exigência de fronteira e o tempo médio despendido em cada uma delas. Por fim, calculou-se o tempo médio da importação pelo Porto de Santos. 0 resultado foi, então, contraposto às informações disponibilizadas pelo Banco Mundial (evidenciadas na Tabela 1).
Os principais dados apresentados neste artigo provêm da pesquisa em campo realizada com profissionais do setor e de instituições governamentais, com os quais a interação se deu por meio do contato pessoal, sob a forma de entrevistas.

\section{Resultados e discussões}

$\mathrm{Na}$ primeira etapa da metodologia da pesquisa foram identificados os procedimentos de fronteira aplicados às cargas conteinerizadas importadas por via marítima. Foi notado que parte dos procedimentos de fronteira corresponde aos procedimentos aduaneiros, conduzidos pela aduana para a nacionalização da mercadoria. Ademais, observou-se a existência de outros procedimentos ou práticas imprescindíveis para a importação, os quais encontram-se listados na sequência:

- Licenciamento de importação:A licença de importação (LI) corresponde a um documento necessário para a importação, sendo conferido por órgãos anuentes do governo brasileiro (listados na Tabela 2). Por meio desse procedimento, o governo brasileiro controla a entrada de uma parcela das mercadorias, sendo somente obrigatório para as mercadorias listadas no site do Ministério do Desenvolvimento, Indústria e Comércio Exterior (MDIC). Assim, quando a licença é aplicada, pode envolver uma etapa de anuência prévia ao embarque do contêiner no exterior (modalidade pré-embarque) e/ou após sua chegada ao porto brasileiro (modalidade pós-embarque). Nesse útlimo caso, é imprescindível a inspeção da carga conteinerizada pelo órgão anuente;

- Despacho aduaneiro de importação: Esse procedimento estabelece o início da nacionalização, sendo composto

Tabela 2. Agentes anuentes de cargas na importação.

\begin{tabular}{|c|c|}
\hline Ministérios & Órgão anuente \\
\hline Ministério da Saúde & - Agência Nacional de Vigilância Sanitária (ANVISA) \\
\hline Ministério da Agricultura, Pecuária e Abastecimento & - Sistema de Vigilância Agropecuária Internacional (VIGIAGRO) \\
\hline Ministério do Meio Ambiente & - Instituto Brasileiro do Meio Ambiente e dos Recursos Ambientais (IBAMA) \\
\hline Ministério de Minas e Energia & $\begin{array}{l}\text { - Agência Nacional de Energia Elétrica (ANEEL) } \\
\text { - Agência Nacional de Petróleo, Gás Natural e } \\
\text { - Biocombustíveis (ANP) } \\
\text { - Comissão Nacional de Energia Nuclear (CNEN) } \\
\text { - Departamento Nacional de Produção Mineral (DNPM) }\end{array}$ \\
\hline $\begin{array}{l}\text { Ministério do Desenvolvimento, Indústria e } \\
\text { Comércio Exterior }\end{array}$ & $\begin{array}{l}\text { - Departamento de Operações do Comércio Exterior (DECEX) } \\
\text { - Superintendência da Zona Franca de Manaus (SUFRAMA) } \\
\text { - Instituto Nacional de Metrologia, Qualidade e Tecnologia (INMETRO) }\end{array}$ \\
\hline Ministério da Justiça & - Departamento de Polícia Federal (DPF) \\
\hline Ministério da Defesa & $\begin{array}{l}\text { - Diretoria de Fiscalização de Produtos Controlados (DFPC) do Exército Brasileiro } \\
\text { - Comissão de Coordenação do Transporte Aéreo Civil (COTAC) }\end{array}$ \\
\hline Ministério da Cultura & • Agência Nacional do Cinema (ANCINE) \\
\hline Ministério da Comunicação & - Empresa Brasileira de Correios e Telégrafos (ECT) \\
\hline Ministério da Ciência e Tecnologia & - \\
\hline
\end{tabular}


pelo preparo da Dl, a Declaração de Importação, que é submetida à parametrização pela RFB. Nessa prática são designados canais de conferência aduaneira, que culminam com o término do despacho ou com o estabelecimento de outras exigências aduaneiras;

- Desembaraço aduaneiro de importação: Demarca o término da nacionalização, sendo composto pela análise documental e pela conferência física do contêiner por parte do fiscal da RFB;

- Controle de pragas: Para a liberação do contêiner ao importador é comum a inspeção prévia da carga conteinerizada pelo VIGIAGRO, para o controle de pragas, o que pode acontecer em diferentes momentos na importação. Esse agente é responsável pelo controle fitozoossanitário do país e realiza vistorias às cargas conteinerizadas para coibir a entrada de pragas ao país, já que o comércio conteinerizado permite o acondicionamento e o transporte delas com facilidade. Esse procedimento é impeditivo para a liberação do contêiner ao importador, devendo acontecer junto à nacionalização;

- Despacho para trânsito aduaneiro: Quando se almeja deslocar cargas conteinerizadas com conteúdo estrangeiro entre recintos alfandegados faz-se necessário requisitar um documento especial denominado DTA - Declaração para Trânsito Aduaneiro -, concedido pela RFB. Há casos em que a remoção do contêiner do Porto de Santos pode ser feita pela DT, Declaração de Trânsferência, um documento cuja obtenção é mais simples que a DTA.

Desse modo, com base nos procedimentos descritos acima, esquematizou-se, na Tabela 1, as etapas burocrática e fiscalizatória recorrentes na importação brasileira:

Por meio da Figura 1 pode-se notar que o licenciamento de importação corresponde ao primeiro procedimento burocrático na importação. Foi representado, entretanto, somente sua parcela relativa à fiscalização pós-embarque, visto que deve ocorrer no país após a chegada do contêiner ao porto. Tal carga conteinerizada pode permanecer no local de descarregamento ou ser removida para outra instalação alfandegada (por meio do despacho para trânsito aduaneiro ou transferência). Desse modo, o importador pode dar início ao procedimento de nacionalização por meio do registro da DI (declaração de importação), procedimento esse que é finalizado com o desembaraço aduaneiro de importação. Por fim, é feito o controle de pragas pelo VIGIAGRO (quando aplicável) e realizada uma conferência física ao contêiner e aos documentos pela Receita Federal para a liberação para saída do recinto alfandegado.

Quanto ao fluxo físico das cargas conteinerizadas pelo Porto de Santos, suas opções logísticas foram representadas na Figura 2, segundo Furlan (2013).

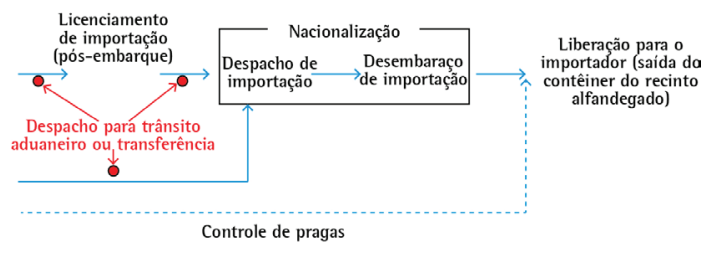

Figura 1. Mapeamento do fluxo burocrático/fiscalizatório para a importação brasileira de cargas conteinerizadas.

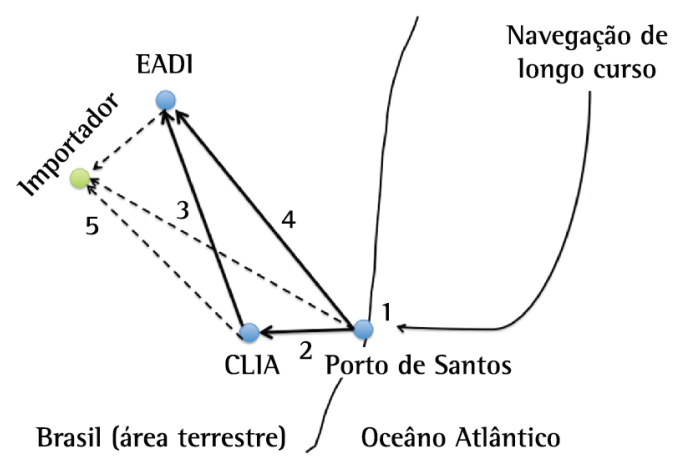

Figura 2. Opções logísticas que as cargas conteinerizadas podem assumir na importação pelo Porto de Santos. Fonte: Furlan (2013).

Notou-se, entretanto, que o tempo despendido para a liberação do contêiner para transferência a um recinto alfandegado externo ao Porto de Santos é irrelevante comparado ao tempo total de importação. Porém, o tempo para deslocamento do contêiner entre instalações alfandegadas é significativo, embora sua mensuração esteja fora do escopo desta pesquisa. Após embarque dos contêineres no exterior para navegação de longo curso, as opções logísticas que eles podem assumir após desembarque no Porto de Santos são:

- Nacionalização nos recintos alfandegados do Porto de Santos;

- Transferência dos contêineres para os CLIAs (recintos alfandegados de zona primária externos ao Porto de Santos);

- Trânsito aduaneiro dos CLIAs para as EADls (portos secos localizados dispersamente no território nacional);

- Trânsito aduaneiro direto do Porto de Santos para as EADls;

- Transporte da mercadoria nacionalizada para o importador (demarcada pelas linhas tracejadas).

Foi observado que parte das cargas conteinerizadas (40\%) permanece nas instalações alfandegadas do Porto de Santos para ali serem nacionalizadas. A outra parte (60\%), porém, é removida para os CLIAs localizados perto do porto organizado marítimo (em 2) ou transferida para as EADls (em 4). Observou-se que a maior parte dos contêineres é movida para os 
CLIAs (44\% do total importado por Santos), sendo que parte deles são dali transferidos para as EADls (em 3). Por fim, em 5, retratou-se a operação de liberação da carga conteinerizada para o importador após a nacionalização.

A Tabela 3 contém a distribuição das cargas conteinerizadas por opção logística ilustrada na Figura 2.

Para a identificação dos procedimentos ou práticas críticas, já na segunda etapa da pesquisa foram estudadas sua frequência de ocorrência e o tempo despendido em cada uma:

- Licenciamento de importação: Somente o licenciamento de importação com anuência pós-embarque pode ser considerado crítico sob o ponto de vista logístico devido à imprescindibilidade de ocorrência do inspecionamento após a chegada da carga no país. Essa modalidade incide em aproximadamente 10\% das importações brasileiras (segundo pesquisa com despachantes aduaneiros), tendo prazo máximo de 60 dias corridos após o descarregamento do contêiner, seu tempo médio é de 12 dias úteis (segundo pesquisa com despachantes aduaneiros);

- Despacho e desembaraço aduaneiro de importação: Ambos os procedimentos correspondem à nacionalização. Segundo Furlan (2013), demora-se, em média, dois dias úteis no despacho de importação caso a parametrização executada pela RFB corresponda ao canal verde ou amarelo (80\% dos casos), ou cinco dias úteis caso seja vermelho ou cinza (20\% dos casos). Posteriormente, no desembaraço aduaneiro, costuma-se demorar um dia útil, independentemente do tempo demandado no despacho de importação. Por fim, após o término da nacionalização, demora-se, em média, mais meio dia útil para a liberação da carga conteinerizada para saída do recinto alfandegado, pois a RFB deve proceder a nova inspeção do contêiner e a análise documental. Essa etapa foi considerada crítica pelo tempo demandado e pela alta frequência;

- Controle de pragas: Essa inspeção ocorre em grande parte dos contêineres (possui alta frequência), pois são abrigatoriamente inspecionados contêineres provenientes de 15 países (incluindo-se os maiores exportadores para o Brasil, dentre eles: China, EUA, Cingapura). Segundo entrevista com fiscais federais agropecuários do VIGIAGRO, as inspeções são

Tabela 3. Distribuição das cargas conteinerizadas por opção logística ilustrada na Figura 2.

\begin{tabular}{cc} 
Opção logística & $\begin{array}{c}\text { Participação do fluxo total de importação de } \\
\text { carga conteinerizada por Santos (\%) }\end{array}$ \\
\hline 1 & 40 \\
2 & 44 \\
3 & 10 \\
4 & 6 \\
\hline
\end{tabular}

Fonte: entrevista com ABEPRA; Furlan (2013). aplicadas em cerca de 70\% do fluxo de importados pelo Porto de Santos, podendo ser conciliadas com outras inspeções. Em conjunto com fiscais federais agropecuários e despachantes aduaneiros, foi possível estimar um tempo médio de ocorrência do procedimento de três dias úteis;

- Despacho para trânsito aduaneiro: Esse procedimento acontece apenas quando há trânsito aduaneiro do contêiner para recinto alfandegado de zona secundária, chegando a demorar um dia útil. Para os casos em que há transferência dele, utiliza-se um outro documento (a DT), o qual demora poucas horas (a maior parte das movimentações demandam esse tipo de documento). Portanto, devido à baixa frequência e ao pouco tempo envolvido, essa etapa não foi considerada crítica.

A Figura 3 apresenta as possíveis combinações das exigências burocráticas e fiscalizatórias para a importação de cargas conteinerizadas por Santos. Ela classifica os procedimentos em três momentos: (1) prévio à nacionalização; (11) nacionalização; (111) complementar à nacionalização.

Para a elaboração da Figura 3 foram consideradas as etapas críticas comentadas acima, além dos valores apresentados anteriormente quanto à frequência de ocorrência de cada etapa. 0 tempo calculado para cada combinação corresponde à média ponderada da frequência de ocorrência com o tempo estimado em cada etapa. Por fim, obteve-se um valor médio estimado para as importações brasileiras de cargas conteinerizadas pelo Porto de Santos.

Com base nos valores dispostos na Figura 3, os principais procedimentos ou práticas identificados como críticos foram:

- Licenciamento de importação (modalidade pós-embarque): Quando incidente, aumenta o tempo de importação para mais de 15 dias úteis. As importações sem anuência de importação (pós-embarque) são conduzidas geralmente em até 10 dias úteis;

- Parametrização (na etapa do despacho aduaneiro): A parametrização consiste numa prática crítica pois é imprevisível o canal que será designado pela RFB - além de o fato ocorrer em todas as importações. Desse modo, a carga conteinerizada fica suscetível à retenção;

- Controle de pragas: Crítico ao processo pela alta incidência (70\% dos casos);

- Saída dos contêineres: Crítico pois induz repetibilidades fiscalizatórias em todas as importações. Mesmo após os procedimentos de nacionalização, os contêineres são novamente expostos ao controle da RFB para avaliação da carga e dos documentos para que possam ser liberados ao importador.

Comparando-se o valor encontrado (de 7,4 dias úteis para as importações brasileiras) com o 


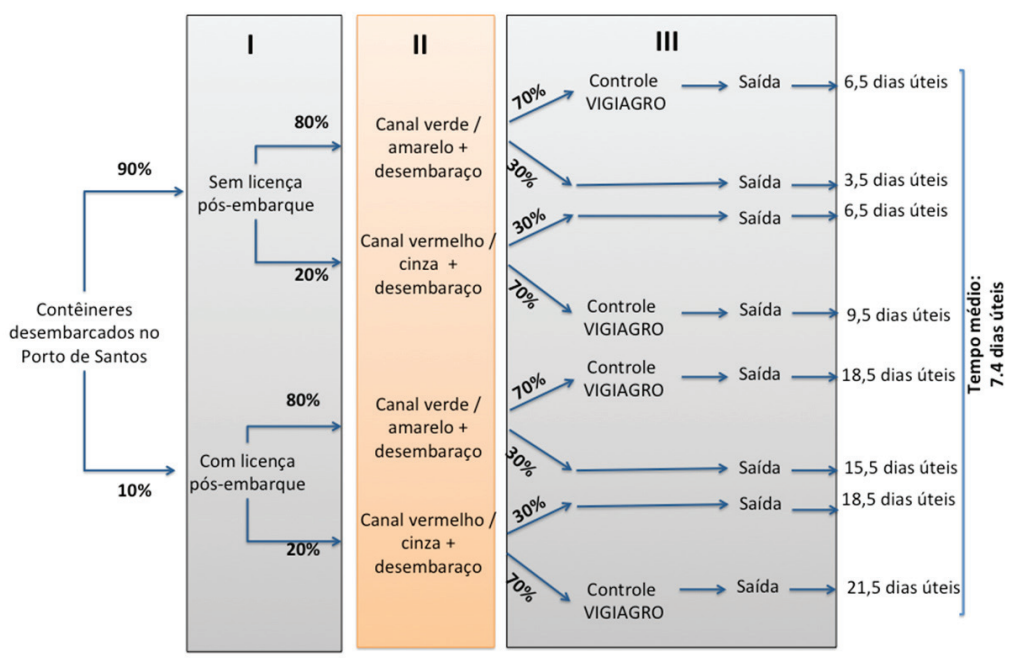

Figura 3. Tempo médio despendido na nacionalização de cargas conteinerizadas.

disponibilizado pelo Banco Mundial, foram notadas algumas diferenças:

- Unidade de medida para aferir o tempo: Os estudos do Banco Mundial utilizam "dias", ao passo que a presente pesquisa utilizou "dias úteis". Isso porque as inspeções físicas são conduzidas apenas em horário comercial, o que não é de praxe nos portos dos países mais desenvolvidos. Neles, as operações costumam ser ininterruptas.

Como os valores aferidos pelos estudos são de até cinco dias, esses serão considerados como "dias úteis" para efeito de comparação com os valores identificados por esta pesquisa (caso contrário deveriam ser considerados os finais de semana no cálculo).

- Restrição da avaliação do tempo do despacho aduaneiro (no estudo Connecting to Compete): Os valores de dois e cinco dias fornecidos pelo Connecting to Compete estão em linha ao tempo demandado pelas etapas de despacho de importação quando os canais de parametrização são, respectivamente, verde/ amarelo e vermelho/cinza. 0 desembaraço aduaneiro, porém, que também é parte da nacionalização, demanda, em média, um dia útil adicional, o que não foi considerado no valor proposto pelo estudo. Adicionalmente, não foram considerados no cálculo os procedimentos preliminares ou complementares à nacionalização, que também são mandatórios para a liberação dos contêineres;

- Não inclusão do tempo despendido no licenciamento de importação pós-embarque: 0 Doing Business estabeleceu um tempo médio de importação de quatro dias para nacionalização e controle técnico, o que foi avaliado como insuficiente para o caso brasileiro. Somente um caso na importação brasileira encaixa-se no valor proposto pelo Banco Mundial: importação isenta de licenciamento de importação pós-embarque, com parametrização nos canais verde/amarelo, isenta de controle de pragas pelo
VIGIAGRO (3,5 dias úteis). Para os outros casos, o tempo para as importações variam de 6,5 a 21,5 dias úteis, podendo exceder o período contabilizado caso algum procedimento se estenda.

Outro ponto notado foi a diferente abordagem por parte do Banco Mundial ao referir-se à nacionalização e aos procedimentos preliminares/complementares. A abordagem do Connecting to Compete (nacionalização com ou sem inspeção) abre margem para conflito ao classificar a nacionalização com ou sem inspeção física. Isso porque toda nacionalização feita no país conta com inspeção física do contêiner: a RFB o certifica em conjunto com a documentação de importação na etapa de desembaraço aduaneiro. No despacho aduaneiro, entretanto, pode ocorrer ou não a inspeção física, a depender do canal de parametrização, sendo esse o momento objeto de análise do estudo. Por outro lado, o Doing Business explora um termo mais abrangente (nacionalização e controles técnicos), o que engloba a nacionalização e os procedimentos para controle técnico da importação.

\section{Considerações finais}

A importação de cargas conteinerizadas pelo Porto de Santos conta com procedimentos críticos que não fazem parte do processo de nacionalização. Ou seja, foi notado que o licenciamento de importação pós-embarque é crítico à importação (quando aplicável), correspondendo a uma etapa prévia à nacionalização. Já, na nacionalização, a parametrização pela RFB é imprevisível, sendo, portanto, crítica ao processo. Por fim, como procedimentos complementares à nacionalização aparecem o controle de pragas pelo VIGIAGRO e o controle para a saída do contêiner do recinto alfandegado após nacionalização. Desse modo, com base na pesquisa realizada, concluiu-se 
que há uma série de outros procedimentos ou práticas diferentes da nacionalização que culminam com atrasos e retenção da carga conteinerizada na importação por Santos.

Os autores sugerem que a etapa de nacionalização não deve ser vista apenas como o despacho e o desembaraço aduaneiro mas ser encarada como um conjunto de etapas burocráticas e fiscalizatórias imprescindíveis para a liberação do contêiner para o importador. lsso porque o uso restrito do termo “nacionalização" prejudica a compreensão do encadeamento das etapas burocráticas e fiscalizatórias, retratando parcialmente a importação brasileira. Sugere-se a expansão do termo para os procedimentos preliminares à nacionalização, que incluem o licenciamento de importação, e aos procedimentos complementares da nacionalização, que incluem o controle de pragas do VIGIAGRO. Embora esse último procedimento não seja exigido no desembaraço da carga, ele é impeditivo para a liberação do contêiner na saída do recinto alfandegado para o importador.

Por fim, os valores mensurados são preocupantes, pois variam consideravelmente (de 3,5 dias úteis a 21,5 dias úteis), contribuindo com imprevisibilidades nas cadeias de suprimentos com conteúdo importados. A média calculada (7,4 dias úteis) é alta e muito distante da dos países desenvolvidos, que costumam despender um dia nos procedimentos aduaneiros. Os autores Souza \& Burnquist (2011, p.113) defendem as ações para facilitação das operações do comércio exterior brasileiro, as quais podem "trazer mais agilidade e menores custos para os exportadores e importadores do país, além de ampliar a competitividade da indústria nacional".

Os valores aferidos nesta pesquisa são suscetíveis a consideráveis variações. A principal fonte para alteração do valor médio consiste no tempo demandado para a anuência do licenciamento de importação pós-embarque, já que o prazo máximo para o procedimento é de 60 dias corridos da chegada do contêiner ao país. Nos cálculos, foram considerados 12 dias úteis.

\section{Referências}

Agência Nacional de Transportes Aquaviários - ANTAQ. (2010). Análise da movimentação de cargas nos portos organizados e terminais de uso privativo. ANTAQ. Retrieved from http://www.antaq.gov. $\mathrm{br} / \mathrm{portal} / \mathrm{Anu}$ arioEstatisticoAquaviario/pdf/ AnalisedeMovimentacaodeCargas2010.pdf.

Arvis, J.-F., Mustra, M. A., Ojala, L., Shepherd, B., \& Saslavsky, D. (2012). Connecting to Compete 2012: Trade Logistics in the Global Economy - the Logistics Performance Index and its Indicators. Washington: World Bank.

Brasil. Ministério do Desenvolvimento, Indústria e Comércio Exterior - MDIC. (2012). Agentes anuentes de cargas do comércio exterior brasileiro. Retrieved from http://www.mdic.gov.br//sitio/interna/interna. php?area $=5 \&$ menu $=246$.

Djankov, S., Freund, C., \& Pham, C. S. (2006). Trading on Time. World Bank Policy Research Working Paper.

Fleury, A., \& Fleury, M. T. L. (2011). Brazilian Multinationals: Competences for Internationalization. Cambridge: Cambridge University Press. http://dx.doi.org/10.1017/ CB09780511933844

Furlan, P. K. (2013). Análise dos procedimentos operacionais e burocráticos dos portos brasileiros: estudo de caso do Porto de Santos (Dissertação de mestrado). Universidade de São Paulo, São Paulo.

Iwanov, T., \& Kirkpatrick, C. (2009). Trade Facilitation and Manufactured Exports: is Africa Different? World Development, 37(6), 1039-1050. http://dx.doi. org/10.1016/j.worlddev.2008.09.014

Penha, L. F. R. (2010). Os Centros Logísticos e Industriais Aduaneiros e a atual indústria paulista (Dissertação de mestrado). Universidade de São Paulo, São Paulo.

Vianna Junior, E. O. (2009). Modelo de Gestão e Automação dos Portos Brasileiros (Tese de doutorado). Escola Politécnica, Universidade de São Paulo, São Paulo.

Souza, M. J. P. D., \& Burnquist, H. L. (2011). Facilitação de Comércio e Impactos sobre o Comércio Bilateral. Estudos Econômicos, 41(1), 91-118.

World Bank, \& International Finance Corporation - IFC (2013). Doing Business 2013: Making a Difference for Entrepreneurs. Washington: The World Bank.

\title{
Identification of critical border procedures in the import of containerized cargoes: study of the Port of Santos
}

\begin{abstract}
This paper identified key practices or procedures performed by the Brazilian government, which slow or delay the import of containerized cargo through the Port of Santos. The research was conducted in two phases: (1) the identification of the main logistics routes and border procedures and (2) the identification of the interrelation between physical and bureaucratic flows. The analysis focuses on customs procedures, which include nationalization and its preliminary or complementary procedures. Multiple procedures and practices were shown to cause delays and retention of containerized cargo, possibly due to nationalization.
\end{abstract}

Keywords

Clearance procedures. Containerized cargos. Time. 